\title{
Reflections on Uncertainty in Economics
}

\author{
by Walter A. Weisskopf*
}

\section{Universal uncertainty}

If an economist talks to a group of distinguished insurance executives about uncertainty, he is expected to confine himself to the many uncertainties of our present economic situation. When I extend my discussion beyond the realm of economics I have two excuses : first, I am not an economic technician or even a theorist of the traditional type but a "Geisteswissenschaftler", a humanist concerned with what Joan Robinson has called " economic philosophy" ; secondly, I believe that our present economic predicaments are related to factors beyond the economic sphere.

Looked at from a universal point of view, uncertainty is an ineluctable element of human existence, part of the position of man in nature and universe. It is rooted in human finitude, mortality, and ignorance. On all levels of his existence man is embedded in the unknown. As Eric Voegelin, one of the foremost metaphisicians of our time, has put it :

"God and man, world and society form a primordial community of being. It is a datum of experience insofar as it is known to man by virtue of his participation in the mystery of his being. It is not a datum of experience insofar as it is not given in the manner of an object of the external world but is knowable only from the perspective of participation in it." 1

Thus man perceives the world as an open, indeterminate system, not as a detached outsider but as a participant :

"Man is not a self-contained spectator. He is an actor playing a part in the drama of being... committed to play it without knowing what it is... the role of existence must be played in uncertainty of its meaning, as an adventure of decision on the edge of freedom and necessity." 2

* Professor Emeritus of Economics, Roosevelt University; formerly Visiting Professor of Economics at Stanford University. pp. $1 \mathrm{ff}$.

${ }^{1}$ Eric Voegelin, Order and History, Vol I (Baton Rouge : Louisiana State University Press, 1956)

\footnotetext{
${ }^{2}$ Voegelin, loc. cit., p. 5.
} 


\section{SEVENTH ANNUAL LECTURE}

OF THE GENEVA ASSOCIATION

(INTERNATIONAL ASSOCIATION FOR THE STUDY OF INSURANCE ECONOMICS)

by

\section{WALTER A. WEISSKOPF}

Professor Emeritus of Economics, Roosevelt University of Chicago Visiting Scholar at the Stanford University

on

\section{REFLECTIONS ON UNCERTAINTY IN ECONOMICS}

Thursday, September 22nd, 1983

$$
4.00-6.00 \text { p.m. }
$$

\section{INTERNATIONAL CENTER FOR THEORETICAL PHYSICS \\ Miramare - Trieste \\ Strada Costiera 11}

Chairman and Discussant :

- Dr. Fabio PADOA, Honorary President of the Geneva Association

Discussants :

- Prof. René PASSET, Université de la Sorbonne, Paris

- Dr. Baruch BERLINER, Swiss Reinsurance Company, Zurich

- Dr. Orio GIARINI, Graduate Institute of European Studies, Geneva

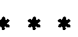

A Conference will follow this Lecture at 6.00 p.m.

$$
\text { by }
$$

SIR KARL POPPER

on

\section{POSTSCRIPT TO THE LOGIC OF SCIENTIFIC DISCOVERY}

Sponsored :

- The Club of Rome

- The International Center for Theoretical Physics

- The International School for Advanced Studies

- The Trieste International Foundation for Progress and Freedom in Sciences 
We are participants - but we are also conscious of our participation. Our thinking, feeling and willing and our actions are part of the system, and stand in reciprocal interaction with other elements of the system. Our very existence, actions and observations have an effect on ourselves and on the system.

Here, the basic human situation is seen in a way comparable to the so-called Heisenberg principle according to which reality is changed by the method of observation. In the social sciences and economics this has been expressed in terms of unintended consequences of human action and in terms of self-fulfilling expectations. Today we are also more aware of uncertainty and indeterminacy because we have doubts about the traditional belief systems which appeared to give us some certainty. Be this as it may, we have to realize that uncertainty, indeterminacy and ignorance are essential aspects of the human situation, not merely the result of specific social institutions.

Our age has been called the age of anxiety. Kierkegaard has pointed to the ontological roots of this anxiety as an essential part of human being. It stems from our being thrown into an unknown world and from having to struggle continuously with the mystery, the uncertainty and the meaninglessness of our life. Our anxieties, centering around our obsession with forecasting, can ultimately be traced back to the impredicability of the time of our death, combined with the fact that the only certainty which human beings have is death itself. Certainty and uncertainty about death are equally at work to make us anxious. (In parenthesis it should be observed that the insurance business, especially life insurance, is involved in these uncertainties and anxieties.)

\section{Symbolization and Belief Systems}

Man protects himself against these anxieties through belief systems which attempt to make the essentially unknowable order of being intelligible as far as possible through the creation of symbols. They interpret the unknown by analogy with the supposedly known. They have a cognitive and normative aspect. They try to explain the mysterious reality (the cognitive aspect) and they try to establish guidelines for action and behavior (the normative aspect). Their function can be classified as follows :

a) Belief systems try to harmonize the world outlook of their times and to eliminate inner contradictions and conflicts ;

b) they try to eliminate value conflicts between individuals, classes and social groups, and value conflicts in the inner life of individuals;

c) they aim at the establishment of norms (values) for behavior and of ultimate ends for individuals and societies ;

d) they try to legitimize and justify the existing values and institutions by investing them with meaning.

Belief systems serve to make the mystery, the unknown, the uncertain comprehensible by giving it a name. A. H. Maslow believed that belief systems satisfy a basic human "safety" need, a need for a "world philosophy that organizes the universe and man into some sort of meaningful whole" 3 . Belief systems reduce the anxiety created by

${ }^{3}$ A. H. Maslow, Motivation and Personality (New York: Harper \& Brothers, 1954), p. 188. 
uncertainty, ignorance and mystery. They are not merely creations of individuals, they are socially generated and become skeletons of societies and cultures. They take the form of mythologies, cosmologies, religions, theologies and philosophies. In modern Western civilization the appear in the form of "science" and social ideologies.

Belief systems from different historical periods are incommensurable. That does not mean that they have no " truth value". They are "true " under the conditions from which they emerge, including the experiences of their authors who are enmeshed in the conditions of their time, however unlikely such experiences may appear under different historical conditions. Moses saw the Divine in the burning thornbush and the early Christians saw the Spirit descending on the disciples at Pentecost. Adam Smith saw the beneficial invisible hand in the working of the markets all around him. Similarly, Descartes and Newton saw the universe as a divinely regulated clockwork. All these belief systems refer to "things unseen ". They all imply some kind of " invisible hand ", and must, by necessity, be based on " faith ". From the point of view of Western scientific world outlook " faith " is inferior to scientific truth; but this again is a projection of the scientific paradigm into a different system. The devaluation of faith as a source of truth is part of Western reductionism. Today, in this period of abandonment of the traditional rationalist and mechanistic paradigm we have come to acknowledge that e.g. the belief in the free market or the belief in the overall planning also rest on "faith".

Are we then exposed to complete relativism in respect to belief systems? The function of these systems is to assuage anxiety created by the uncertaint and the unknown. Central belief systems are "valid" insofar they perform this function effectively. It is, of course, difficult to test this kind of efficiency. One is reduced to examine the viability and stability of a social order, an ephemeral and elusive yardstick. This measure also raises almost insoluble problems : was the world outlook of National Socialism and of Italian fascism a valid viable belief system as long as it supported a relatively stable social order? Do we have to accept it for that time and place as viable and valid? The answer is obviously a resounding "no"; an answer which, however, can only be given from the standpoint of a democratic, liberal, pluralistic value and belief system. This answer is valid and " true " for those who accept, are committed to and are conditioned by such a system.

\section{Freedom and necessity}

It is perhaps logically inconsistent to mention commitment and conditioning in one and the same statement ; but it is ontologically consistent. A realistic analysis of the human condition will have to see man as a "Gestalt ", a whole, a centered unity and as free. $\mathrm{He}$ is free because his consciousness enables him to know that he "is". Through his consciousness man can put himself outside the given actuality, grasp potentialities, remember the past, envision the future. However, this freedom is conditioned and finite ; it is limited freedom. That does not only imply that man cannot transgress certain limits but more so that he, the free subject, is a conditioned being, subject to necessity. Man, as a person, a centered self is a finite, mortal bundle of physical, psychological, historical, social, economic, hereditary and environmental conditions. This conditioned person is free to make choices and commitments within the limits of the conditions which form his person. 
All this applies to belief and value systems. We are free to embrace a value system but we are also conditioned by such systems. We find here a typical relation of circular interdependence where freedom and necessity mutually determine each other, each being cause and effect at the same time. It is a situation which in physics was called "complementarity" by Niels Bohr. Freedom and necessity (called destiny by the theologian Paul Tillich) are complementary factors in human existence. Thus, the truth value of a belief and value system and its validity is established by the free choice of people who are in themselves conditioned and subject to all the limitations of their existence. This is not relativism but a cogent conclusion from the insight in the human situation. NO TRUTH IS UNIVERSAL IN THE SENSE THAT IT APPLIES AT ALL TIMES AND TO ALL HUMANKIND. Mortal, finite human beings cannot possess the omniscience of a deity. The idea that they do, often harbored explicitly or implicitly by scientists and by modern intellectuals, is hubris and megalomania. It is caused by the difficulty of embracing convictions with the recognition that we who commit ourselves are conditioned beings. One has to accept the fact that we have to embrace thoughts and values as absolutely valid for us under the conditions of our existence but that the same applies to others whose ideas and values are different because they are subject to different conditions. Like all human phenomena, truth and validity are subject to freedom and necessity. We must believe in our ideas and values "absolutely" with the awareness of their limitations. The logical impossibility of this situation does not preclude its ontological validity.

\section{The economic belief system and its historical development}

To return to our basic topic : the role of uncertainty in economic thought. When we call economics a belief system we do not imply that it is not a "science" because we have classified the sciences as belief systems. Like all belief systems economics comprises cognitive and normative elements. To understand this, one has to proceed historically: the function of economics as a belief system has changed with changes in the character of the economic system; and these changes in economic reality were reflected and are mutually interdependent with changes in the two aspects of the economic belief system : with changes in value-attitudes on the one hand, and with changes in the cognitive paradigms on the other hand. We shall analyze the interrelations between the following factors : changes in the character of capitalism from a relatively free market system to one in which control and power play an increasing role; changes in the value-attitudes from impulse control to consumerist hedonism; and, last but not least, the changes from a Cartesian, Newtonian, mechanistic deterministic cognitive paradigm to a Heisenbergian, holistic, indeterminate structure of thought. These developments are circularly interdependent ; each one is at the same time cause and effect of the other ones.

19 th century capitalism was (more or less) competitive, individualistic, ownercontrolled, with small-scale firms. Prices and incomes fluctuated relatively freely in response to supply and demand in an economy of relative scarcity, therefore pre-occupied with the increasing production of physical goods.

20th century capitalism is organizational, corporate, managerial, with economic power exercized by big business, labor unions and governmental agencies. This economy of large productive capacity is preoccupied with selling and with stimulating consumers' 
demand and desires. Correspondingly, economics developed two types of value systems and two cognitive paradigms.

In the 17th and 18th centuries the value system underlying the emergence of the market economy was the Protestant-Puritan work and success ethics with its worldly asceticism, its stress on savings and austere consumption, its individualistic competition. This value system was a defense-mechanism against the conflicts between Christian ethics, still at work in the minds and hearts of people, and the behavior required by the new market economy. Everything this economy required was considered as hubris and concupiscence by Christian ethics : capital accumulation, a book-keeping orientation towards life, purely technical and economic rationality, acquisitive striving, pre-occupation with material success in terms of money, avoidance of all cooperation, community, compassion and neighborly love.

These moral conflicts were aggravated by the destruction of the traditional system of prices and incomes which had remained relatively stable for centuries. Much of classical and neoclassical economic thought was - mostly unconsciously - devoted to assuage these anxieties. The idea of the invisible hand served to eliminate the conflict between individual and social goals by assuming their identity. This was accomplished already by Adam Smith who defined the goals of individual self-interest and the public good in the same way: as increase in the production of physical goods. This is still the corner-stone of the free enterprise ideology : it gives a moral legitimation to the gain- and profit motive ; the individual can strive for more and more with a good conscience because he benefits not only himself but also promotes the public good. This is also the root of the trickle-down theory which today conservative governments use as a rationale to render favors to big business. It is also the root of the idea of economic growth defined in terms of more and more physical goods.

The labor theory of value is known predominantly because Marx used it to attack the legitimacy of profits. However, it was also used by Adam Smith, Ricardo and by British classical economics - all approving the free market system. Its real importance lies in its ethical content : it aims at proving that values and prices of goods are higher or lower in proportion to the amount of labor used in their production. Translated into moral terms this implies that rewards are commensurate with effort. This idea is still alive in such slogans as " who does not work shall not eat ", and " equal pay for equal work" (a slogan used by labor unions long before it became a battle-cry of the feminist movement). If prices and wages were proportional to effort their differences would be justified by merit and achievement. Although this theory was abandoned by marginal unitility theory and by the neo-classicists in the second half of the 19th century, the underlying idea of legitimizing incomes by the amount of sacrifice involved in their earning remained : wages, rent and profits were, and still are, justified by the amount of effort involved ; landlords and entrepeneurs have supposedly a right to rent and profits because their property originally acquired by their or their parents' efforts - contributed to the production of goods. Both, marginalists and neo-classicists, justified interests as a reward for " waiting ", postponing spending for consumption, thus legitimizing interest as a reward for temporary sacrifice of consumption. In this way the market system is made to appear fair and just by rewarding effort and punishing lazyness. Although this approach was obviously disproved in the Great Depression, it has been revived by the conservative movements in the Anglo-Saxon countries today. 
The labor theory of value is also related to the emphasis on growth, expansion and acquisition. More labor leads to the production of more goods and to higher rewards ; thus, the increase in the production of goods, considered as " economic growth " is rewarded and an incentive is provided. That implies that an increase in labor, work, and output is a desirable goal. The classical ideal of welfare is identical with the concept of economic growth for the individual and for society. This idea has lost its validity in our time not only because of the squandering of non-renewable resources, but also because of the satiation of the consumers with products and services which may be subjectively desired but are objectively detrimental to physical and mental health.

This belief system changed during the second half of the 19th century and led gradually and finally to a new moral value system which corresponds to the 20th century phase of capitalism. The link between the classical and the new value system was formed by utilitarian hedonism. This corresponded to the changes in the Western economies. The problem shifted from producing more and more physical goods in economies with little productive capacity to the problem or selling the output of a large productive capacity. Thus, economic thought turned from production to consumption. Marshall's Principles, first published in 1871, was the first comprehensive treatise which contained a part on "consumers and their satisfaction ". Economic value theory turned from a factor- and cost of production theory to a demand and subjective utility value theory. The classics had not been able to solve the paradox of value : things that are very useful like water have no or a low price; whereas things that are much less useful like diamonds have a high price. Thus, they rejected utility to consumers as a source of economic value. The construct of declining marginal utility "solved" this paradox and allowed economic thought to ground economic value in subjective evaluations of consumers. This development was prepared by the utilitarian philosophical radicals who explained human action as determined by the avoidance of pain and the search for pleasure. This was a mechanistic line of thought. The pleasure and pain principle - later called by Freud the pleasure principle - is best exemplified by Pavlov's dog ; it was used by all behavioristic psychology but found its most glaring application in economics.

The classics had a clear idea of the public interest or public good. They interpreted it, for reasons already explained, in terms of an increasing volume of physical goods, a mechanistic approach. However, economics developed in a period of political and cultural individualism. Although Adam Smith is regarded as the father of the idea of economic liberty, he and the other classics did not develop an individualistic subjective theory of consumers' behavior. This was left to the utilitarians and later to the marginalists and neo-classicists who elevated the satisfaction and maximization of subjective consumers' utility to the ultimate goal of the economy. Whereas Adam Smith extolled parsimony and thrift as virtues and condemned prodigality, the utilitarians and marginalists began a line of thinking which, in the mid-20th century, ended in accepting consumerism, limitless consumers' spending, as an ideal. They believed in consumers' sovereignty : consumers determine by their demand what and how much should be produced. The idea of consumers' sovereignty, however, does not take into account the maldistribution of income ; consumers' demand means monetary demand, that is demand of those who have sufficient purchasing power to influence the market. It also presents great difficulties for the determination of social goals. How can an individualistic economic philosophy which fragmentizes society into the subjective desires of innumerable individuals arrive at any concept of the social general good? 
The marginalists and neoclassicists solved this predicament by the combination of utilitarian hedonism with economic rationalism, defining it as maximization of subjective utility. Generalizing this principle Lionel Robbins defined economics as the science of allocating scarce resources to alternative uses in such a way that individual, subjective utility is maximized. He explicitly rejected the idea that the economist should evaluate morally or socially what people consider useful. ${ }^{4}$ Economic rationality becomes completely formalized and void of substantial content. The ideal is maximization of whatever consumers with purchasing power desire. This carries to the limits the justification of the unrestricted market system : it is irrelevant what is produced as long as it satisfies individual consumers' preferences. Social effects on the well-being of the group, on the environment, on physical and mental health, on the good for mankind or even for the nation - everything that falls under the heading of social good, is irrelevant, or at least, falls outside the province of economics. This orientation is by no means extinct. It underlies the policies of conservative Western governments, especially the policies of the present administration in the USA which tries to destroy all environmental, health and welfare restrictions on business according to the slogan of " freedom of the market".

However, there is a remnant of substantial morality left in this formal rationalism of neo-classical economics. Lionel Robbins justifies it by ultimately making an appeal to substantial rationality:

"And thus, in the last analysis economics does depend... on an ultimate valuation the affirmation that rationality and ability to choose with knowledge is desirable. If irrationality, if the surrender to the blind forces of external stimuli and uncoordinated impulses at every moment is a good to be preferred above all others, then it is true that the raison d'être of economics disappears." 5

Here we find, in 1913, the last remnants of the Puritan-Protestant ethics : rationality is impulse control, is the resistence to surrender to blind forces. This idea was still strong at the beginning of the century ; but it lost its force and was overwhelmed by the surrender to the dark forces and external stimuli in the modern consumerist life style. Economic rationality in science, technology and business organization is in conflict with the "irrational" and uninhibited impulses in consumption, with the " hippy" life styles and the licentiousness of sex life and of interpersonal relations of the 20th century culture in the West. Here we find another inner contradiction which creates uncertainty about values, about right and wrong, and a contribution to the anxieties of our time.

The combination of subjectivism and formalized rationalism shows an inner conflict in this historical period. Subjectivism represents an abandonment of the belief in objective values and in objective reason that can understand and explain the order of the universe, and the order of the economy, interpreted as a microcosmos, a small universe. Subjectivism if carried to its extreme, would lead to complete moral and cognitive relativism, anarchism and nihilism. The social thought of the period had to embrace subjectivism because is was rooted in the philosophical and political individualism of the times. It was impossible to return to the beliefs of the Enlightenment with its faith in nature and reason, and to its

4 Lionel Robbins, An Essay on the Nature and Significance of Economic Science (London: Macmillan \& Co., 1913, 1946), pp. 95, 106.

${ }^{5}$ Robbins, loc. cit., p. 157. 
faith that this order is accessible to human reason. Thus it arrived at a compromise formation, a symbiosis of contradictory elements in the concept of formalized reason which tries to use an orderly framework of formal maximization to contain the anarchic forces of subjectivism. This approach represents also a combination of mechanistic with psychological elements. Man is freed from any objective limits to his desires by the stress on consumers' sovereignty ; but he is pressed again into the harness of economic rationality by formal maximization-rationalism. He is supposed to react mechanically (like Pavlov's dog) to pain and pleasure, automatically minimizing pain and maximizing pleasure or utility.

\section{Cognitive paradigms in economics}

I have called the two paradigms (systems of thought) prominent in the history of economic thought the Newtonian paradigm, corresponding to 19th century capitalism on the one hand, and the Heisenbergian paradigm related to 20th century capitalism on the other hand. Neither of these terms should be taken too literally. Economists have not consciously and explicitly referred to either Newton or Heisenberg in their models; nor is there a direct connection between physics and economics. However, the two names illuminate differences between entire world outlooks. The essence of the Newtonian model is that it leads to determinate results and conclusions whereas the Heisenbergian views reality as basically indeterminate.

\section{The Newtonian paradigm}

The Newtonian paradigm underlying classical and neo-classical economics interpreted the economy according to the pattern developed in classical physics and mechanics, in analogy to the planetary system to a machine and to a clockwork : a closed autonomous system ruled by endogenous factors of a highly selective nature, self-regulating and moving to a determinate, predictable point of equilibrium. This brief description requires closer definitions. We are talking here about a system of thought and a framework for the perception and interpretation of reality. A system is "any set whatsoever of jointly considered variables, including the entire world, or any lesser set" ${ }^{6}$ A system is closed if "all variables of such a system are endogenous". "That means that the system includes all variables which are considered relevant ; whatever happens in the system and whatever changes take place is caused by variables which are part of the system. Traditional economics considers such variables as wages, prices, incomes, spending and investment, etc. as endogenous variables involved in economic processes whereas changes in population, technology, and government policies, etc. are considered exogenous variables, not included in the system. This is why the system is called autonomous; it works independently of other systems, governed by laws of its own. Autonomy means that only endogenous variables are considered and exogenous ones are excluded. The Newtonian system is self-regulating: again this is another way of describing its closure. Every thing that is supposed to happen within the system is explained by endogenous variables.

6 Sidney Schoeffler, The Failures of Economics: A Diagnostic Study (Cambridge, Mass. : Harvard University Press, 1955), p. 45.

7 Schoeffler, loc. cit., p. 50. 
The determinateness of the system involves more complicated considerations. If the system comprises the entire world, all variables must, by logical necessity, be endogenous. In this case determinacy means that if all endogenous variables were known, the outcome of processes can be unequivocally predicted. The outcome can be clearly and precisely defined in terms of the known endogenous variables. The Newtonian paradigm represents reality as separate and independent of the observer. Subject and object, thought and reality are distinct, separate, independent spheres. Here is the observer and there is the observed reality. This applies also to action; the actor is distinct from the object and the reality that is acted upon. Determinacy and sharp distinction between observer and actor, and the observed and acted upon reality are mutually interdependent. If observation and action change reality during the process of observation and action, our predictions could not be determinate. Underlying the Newtonian paradigm is the conviction that the detached observer can grasp the observed object with his senses and his reason. Perception and reason establish links with an observable and comprehensible universe. Observer and observed, actor and object are subject to the same comprehensible, knowable laws. The idea of "natural law" is here the intermediate link between subject and object.

The natural laws were laws of causation, causae efficientes. There was no place for causae finales, for ends, goals, aspirations, even ideals, as causal explanatory factors. In spite of the social changes developed during the last 200 years, the predominant Newtonian paradigm remained causal and mechanistic. One has to remember that this philosophy developed in a period that tried to throw off the shackles of traditional religions and political authority; it rebelled against the ruling churches and against the ancien regime. "Ecrasez l'infâme" and "liberty, fraternity and equality" were its slogans. The stress on causae efficientes and the rejection of causae finales was connected with the rejection of the idea that the world serves God's purpose and that men have to carry out the will of God. (This orientation is still alive in the USA in the debate between the evolutionists and the creationists.)

Historically this paradigm was developed during the 16th and 17th centuries in Europe and is connected with the names of Bacon, Descartes and Newton. It would be a mistake to assume that any one of the thinkers of this period, even those of the Enlightenment, represented this paradigm in complete purity. There were differences between the Scottish School of philosophy to which Adam Smith belonged, "les philosophes" in France and Kant and the Kantians in Germany. Even in the natural sciences, in astronomy, physics and mechanics there was a gradual receding of theological ideas in the thought of Copernicus, Kepler, Galileo and Newton. Kant somewhat abandoned the sharp distinction between subject and object, observer and observed in his idea of unknowability of the "thing in itself" (das Ding an sich), of ultimate reality. Nevertheless, the Baconian-Cartesian-Newtonian paradigm ruled all thought in the 17 th, and from the 17 th to the 20 th century. ${ }^{8}$ Especially the empirical approach and use of the mathematical description of nature is reflected in the style of classical economics.

${ }^{8}$ Fritjof Capra, The Turning Point : Science, Society and the Rising Culture (Bantham Books, 1982), pp. $53 \mathrm{ff}$. 
Francis Bacon changed the meaning and the purpose of thought and of science. From Antiquity to the Middle Age this purpose was the grasping of essences, of the nature and meaning of things, "wisdom, understanding and living in harmony with the universe". In modernity the purpose was the domination, control and exploitation of nature. This orientation penetrated only slowly into economic thought. Until the 20th century traditional economists tried to understand the workings of the economic system without trying to change it. This was due less to any remnants of the pre-modern stance than to the conviction that uninhibited market and pursuit of gain would have beneficial results. However, the antagonists of the system, especially Marx, embraced the idea that thought should not only explain but change reality. But even Marshall, and other neo-classicists, recognized the importance of reform and deduced from their equilibrium models that a more equal distribution of income would lead to greater welfare and more total utility. It was, however, left to the 20th century to change economics from a contemplative discipline to the handmaiden of technology and business.

Another aspect of the new paradigm was developed by Galileo and Descartes, that is the distinction between primary and secondary characteristics of things, the primary ones of a purely quantitative nature and of scientific importance, the secondary qualitative ones (like color, sound, taste or smell) were cast out of the realm of scientific discourse ${ }^{9}$. This distinction plays an important role in economics through its emphasis on quantification of all variables and the exclusion of every kind of phenomena which cannot be subject to the " measuring rod of money" (Pigou).

Descartes' belief in the absolute certainty of scientific knowledge was and is still widely accepted, definitely in economic model building. He rejected as unscientific all statements about matters which are not perfectly known and about which there are any doubts. This is diametrically opposed to the ideas of modern physics which considers concepts and theories as limited and approximate. The mechanistic cognitive paradigm also reflects the techniques of early manufacturing. Both the sciences and manufacturing from the 16 th to the 19 th century show the following common traits :

1) abstraction from quality and stress on quantity ; 2) interpretation of the world in quantitative terms; natural and social relations are envisaged as relations between qualitatively homogenous magnitudes, reducible to a common quantitative denominator ; 3 ) a trend towards calculability ; measuring becomes the most important instrument of acquiring scientific knowledge ; 4) a tendency to interpret natural and social phenomena as mechanical processes ; the concepts of force and matter were applied to non-mechanical events ; 5) the atomization of the natural and social world into basic non-divisible units. All this is, as we shall see, reflected in economics, and is part and parcel of the Newtonian certainty-paradigm. Accordingly, the world was interpreted as a machine. "There was no purpose, life or spirituality in matter" ${ }^{10}$.

\footnotetext{
${ }^{9}$ Capra, loc. cit., p. 55.
}

${ }^{10} \mathrm{~W}$. Weisskopf, The Psychology of Economics (Chicago: The University of Chicago Press, and London : Routledge \& Kegan Paul, 1955, also University of Chicago Press, Midway Reprint, 1975), pp. 52 ff. Franz Borkenau, Der Übergang vom Feudalen zum Bürgerlichen Weltbild, (Paris, Felix Alcan, 1934). Capra, loc. cit., p. 55. 


\section{The Newtonian paradigm and economic equilibrium}

The influence of the mechanistic style of thinking is especially discernible in the idea of equilibrium. This idea was still in its infancy in the thought of Adam Smith although he used it implicitly in his theory of actual market prices (in contrast to his labor theory and his natural price theory 11. Smith saw clearly that in reality prices fluctuate continuously ; but the deterministic character of equilibrium is already present in his idea that the price gravitates towards what he called the " natural price" composed of wages, rent and interest, the cost of production. From its very inception the equilibrium concept had a deterministic character and represented Cartesian thinking; it was assumed to establish certainty. Market prices are assumed to move towards an ascertainable center (the cost of production), driven by a force (competition) towards a " point of repose and continuance", a thoroughly mechanistic, planetary, Newtonian model. It was assumed that this equilibrium led to a just and fair distribution because ultimately prices would conform to labor values; they would reward work and effort.

In the thought of Ricardo the mechanistic and deterministic character became more pronounced. His model of the economy works like a machine in which wages, profits (interest) and rent move in definite mathematical variations with each other. In his version of the labor theory of value, labor is interpreted as a physical force which creates goods and values like the force of gravity moves matter. These movements are pre-determined and inevitable. The idea of the iron law of wages and of the inescapable working of the law of supply and demand originated with Ricardo and was taken up by the early socialists. Under Hegelian and Marxian influence they applied this mechanical inevitability of the economic laws to economic development, and concluded that social reform and betterment was futile. They rejected unionism and social legislation as futile, and waited for the downfall of capitalism.

In the same way Malthusian population theory tried to prove the inevitability of poverty by representing the laws of population as ineluctable. They established a mechanical interrelation between wages, subsistence, female fertility and the niggardliness of nature. Higher wages would lead to greater fertility; but further increase in population would be ultimately stopped by the law of diminishing returns. We find here again the prediction of an inevitable certainty and determinacy, definitely in line with Descartes' paradigm of the world as a machine. Economists like Ricardo and Marx viewed the economy as a natural, material phenomenon, and economic processes as mechanical, certain, inevitable and determinate.

\section{Neoclassical equilibrium theory}

In neoclassical equilibrium theory the Newtonian paradigm found its most precise application. We shall briefly discuss this most influential example of this theory as presented by Alfred Marshall ${ }^{12}$. Its cornerstone was the idea of economic rationality.

11 Weisskopf, loc. cit., pp. $28 \mathrm{ff}$.

${ }_{12}$ Alfred Marshall, Principles of Economics (London : Macmillan, first edition 1871, 8th ed. 1920). 
Neoclassical equilibrium theory rests - as has been pointed out - on a belief in rational economic conduct. It requires instrumental rationality which determines the most efficient means for given ends: profits, monetary gains, pleasure, utility, and the maximization of quantifiable and measurable ends. Marshallian theory was to extend rational economic conduct from the individual to the market. It is already doubtful whether an individual person really is propelled in his actions by maximizing economic rationality. What we can observe in reality is haphazard, random stochastic decision making by cutting the Gordian knot in situations of conflict and doubt. Individual decisions are dictated by habit, by peer group example, by pressure, they resemble more the tossing of a coin than rational, deliberate maximization.

The individual economic man is supposed to use the same principle in allocating his resources to present and future wants ; "A prudent person will endeavor to distribute his means between all their several uses, present and future in such a way that he will have in each the same marginal utility" ${ }^{13}$. That means that he will get the same pleasure out of present and expected future consumption. This inclusion of future wants into the model of rational behavior is a clear attempt to make the actually uncertain future certain, to eliminate uncertainty of the future and replace it by a measurable certainty. This is what insurance is doing; however, Marshall does not apply his reasoning to insurance but to actual human conduct. Thus he implicitly eliminates the ground for a theory of insurance which makes sense only if one accepts the actual uncertainty and incalculability of the future. If the future were predictable and calculable, one would not need any actuarial probability tables in the insurance business.

Marshall recognized the problem of uncertainty as one of the main obstacles to his equilibrium scheme. Thus he stated that uncertainty " is an objective property which all well-informed persons would estimate in the same way" ${ }^{14}$. By assuming that all well-informed persons estimate uncertainty of the future in the same way, Marshall implies the possibility of forecasting the future correctly. Uncertainty is minimized, at least intellectually. One could call this thought-construct an intellectual insurance which is cheaper but less effective than the actual purchase of insurance policies.

An important part of the equilibrium model is the principle of diminishing returns. Originally it was derived from technology and only applicable there : if one uses the same number of machines but employs more and more workers, the output will increase at a declining rate and this increase will finally stop. If restricted to purely physical production and under static conditions (some factors of production must remain constant) it is definitely valid. However, it becomes questionable under dynamic conditions. In modern industry with fast and furious technological changes hardly anything ever remains constant ; and if it does, there is general complaints about lack of economic growth and stagnation. Even more questionable is the application of the principle of diminishing returns to psychological processes. Only in the most simple cases will the additional satisfaction from additional consumption and acquisition decline ; e.g. in eating: the tenth potato will taste less satisfying than the first one, even to a very hungry person. However, the principle does not apply to the acquisition of money and possessions in an acquisitive

13 Marshall, loc. cit., p. 119.

${ }_{14}$ Ibid. 
society, nor to more and more comforts, to what is called rising standards of living. ${ }^{15}$ If applied to consumption and psychological processes the principle of diminishing returns, in the form of diminishing marginal utility, serves merely to make possible the construct of a determinate equilibrium which could not be accomplished without it. Again economic thought turns out to be an instrument for the establishment of certainty.

\section{Equilibrium of the market}

Market equilibrium and the idea of a market-clearing price was and still is the cornerstone of economic thinking and of free market ideology. This idea is entirely borne of the desire for stability and certainty. The equilibrium point is the well-known point of intersection of the demand- and supply curves, the first declining, the other ascending so that at their intersection a position of equilibrium will be reached. It can be interpreted as a quasi-religious, ideological construct destined to establish a link between the ideas of certainty and rationality which supposedly support each other. This equilibrium: 1) provides a "center of repose and continuance" for the fluctuations of prices ; 2) it constructs the working of markets in accord with individual rational economic conduct ; 3 ) it is related to the classical ideas of harmony and bears traces of beneficiality and justice ; 4) it seemingly enables the economist to analyze the operation of market forces with scientific precision, with analogies drawn from physics and mechanics, from the law of gravity and the swings of a suspended stone. ${ }^{16}$ All this establishes the certainty and determinacy so intensely desired.

Neoclassical theory took two steps to arrive at a determinate equilibrium solution: first, it looked at the market as if it were an individual. The market, a social phenomenon, was seen as a macro-anthropos, who behaves like a rational economic man. Even if one assumes that an individual always behaves rationally and always maximizes utilities it is entirely unrealistic to assume that the market acts in the same way. Markets are collective phenomena in which a multitude of persons participate; they cannot act like a rational, maximizing individual. In order to accomplish this, perfect knowledge on the part of all market participants was assumed ; if every buyer and seller knows the intentions of every other buyer and seller, he knows the demand curve and the supply curve, and can predict future developments and the final equilibrium price with certainty.

The transubstantiation of the market into a social individual, a macroanthropos, depends on the assumption of omniscience, of perfect knowledge. An individual knows his own mind, at least as far as his conscious conduct is concerned. He is a unity and he can, at least in theory, make free choices between alternative uses of his assets and resources. The unity of the individual is established by inner knowledge. If every marketer has perfect knowledge of the intentions of all other marketers, the market becomes like an individual and, then, can also act like one. This makes it possible to interpret market behavior and individual behavior alike : both result in an equilibrium position that is characterized by

15 Tibor Scitovsky, The Joyless Economy (New York: Oxford University Press, 1976), Walter Weisskopf, Economic Growth and Human Well-being, Quarterly Journal of Economics, Champaign, Illinois, 4/4/2, Summer 1964.

16 Weisskopf, loc. cit., p. 195. 
some kind of equalization and maximization. The individual finds a resting point when his marginal utility and disutility are equal: Marshall uses the example of the berry-picking boy who stops picking berries when his marginal desire to eat is equal to his marginal desire to rest. The market-clearing equilibrium price satisfies the sellers and the buyers who want to sell and buy at this price. By thus clearing the market, it establishes a kind of maximization under the given supply- and demand-conditions.

It is obvious that the assumption of omniscience or perfect knowledge is a wish-fulfilling fantasy. Later economists, therefore, have stressed the hypothetical nature of this assumption and of the equilibrium model which it supports. Marshall, however, represents it as seemingly realistic. He starts out with the assumption of perfect knowledge and concludes that every dealer with such knowledge anticipates the equilibrium price and thus will bring it about. With perfect knowledge the market acts like a decision-making individual. But admitting that perfect knowledge may not be a frequent occurrence, he assumes perfect forecasting or correct guessing of the future by most marketers. When he finally abandons these unrealistic assumptions, he still sticks to the idea of a market-clearing equilibrium price because knowledge of the curves "may begin to spread", again implying knowledge. When such assumptions are abandoned, there is no reason to assume that many exchanges will take place at the market-clearing price unless a special group of buyers and a special group of sellers exchange with each other. The establishment of the equal market clearing equilibrium price requires a certain kind of pairing of buyers and sellers. As I have demonstrated elsewhere, such a specific kind of pairing is an unwarranted assumption. They must pair in such a way that those buyers who do not buy at the equilibrium price are those who want to buy only at a lower price, and that those sellers who could not sell at the equilibrium price are those who only want to sell at a higher price. ${ }^{17}$

If assumptions of perfect knowledge and correct forecasting are abandoned, the establishment of a market-clearing equilibrium price depends on the silent assumption that an invisible hand brings together the right buyers and sellers. Without perfect knowledge and perfect forecasting the product in question (bushels of grain in Marshall's example) would change hands at various prices - of which the market-clearing price is only one of many. The "true " equilibrium price is the one which " if it were fixed on at the beginning and adhered to throughout, would exactly equate supply and demand "18, again a wish-fulfilling chimera. The intellectual construct of a determinate equilibrium position requires the denial of the human condition : denial of interaction with others without knowing their intentions, denial of ignorance of their future actions ; denial of uncertainty and of indeterminacy of events.

All this applies to what classical theory and Marshall calls short-term equilibrium. However, one finds a similar denial and reduction of reality in long-run equilibrium of supply and demand. Here, the static approach is seemingly abandoned and long-run developments in time are considered. From the very beginning, however, the time element is excluded by assuming away any change. The long-run equilibrium price is defined as " the average value which economic forces would bring about if the general conditions of

17 Weisskopf, loc. cit., pp. 200-210.

18 Marshall, Principles, p. 343. 
life were stationary for a run of time long enough to enable them all to work out their full effects" 19 . Here we find again that the fear of uncertainty and of change lead to their protective denial. General conditions are assumed to be stationary; the effects of time and change which are interdependent phenomena are assumed away. This is another way of arriving at omniscience and establish certainty: if we know the existing conditions and then assume no change over time we can predict with certainty ; we are like God "scientes bonum et malum et futura".

The troublesome factor is clearly recognized and acknowledged by Marshall : " he (the observing economist) segregates these disturbing causes whose wanderings happen to be inconvenient, for the time, in a pound called ceteris paribus ". ${ }^{20}$ Although the entire analysis refers to equilibrium in the long-run, the main effect of time, namely change, is excluded by the assumption of " ceteris paribus", that other things will remain equal. The "ceteris paribus" clause is a defense against the dread of uncertainty and against the ravages that time inflicts on human beings. Neoclassical economic theory acts again like an insurer who makes certain that one's financial obligations are fixed and known whatever happens. In a way insurance makes things to remain equal, establishes a reality with a ceteris paribus clause.

Thus it has become clear: the idea of a determinate equilibrium could only be established at the expense of realism by eliminating in thought the elements of uncertainty in the human situation. The neoclassical economists seemed to be driven by a fear of indeterminacy.

Elsewhere I have tried to relate these abstracting methods to psychological processes by which the ego defends itself against unbearable experiences, by the psychological mechanisms of defense discovered by psychoanalysis ${ }^{21}$. By isolation, projection, repression, compensation and denial the ego eliminates unbearable thoughts and feelings and experiences from consciousness.

Fifty years after Marshall's Principles appeared, for the first time Professor Frank $H$. Knight reformulated neoclassical theory with unsurpassed lucidity ${ }^{22}$. According to Knight stable equilibrium and with it certainty and determinacy can be attained only in a "perfect state" which requires a formidable array of abstract, unrealistic assumptions. Foremost among these are complete rationality, perfect knowledge, perfect intercommunication, perfect mobility in space, absence of all cooperation and collusion, no ownership of the means of production by private persons because every productive agent is " an inseparable part of the personal endowment of some member of society"; that means there is no capital and land separate from a person; everybody owns all the capital goods and all the land he needs for his line of production; there is no organized production because every member of society produces a finished product. Under these conditions, admittedly non-existent in real society, risk and profits would be absent because the assumption of

19 Marshall, loc. cit., p. 347.

20 Marshall, loc. cit., p. 366.

21 Walter Weisskopf, Psychological Aspects of Economic Thought, Journal of Political Economy, LVII/4, August 1949.

${ }^{22}$ Frank H. Knight, Risk, Uncertainty and Profit (Boston and New York : Houghton Mifflin Company, 1921; re-issued by the London School of Economics, 1933-1940). 
omniscience, perfect rationality and perfect intercommunication removes all uncertainty ${ }^{23}$. Profit and entrepreneurship exist only because of the uncertainty created by the absence of perfect knowledge. This is Knight's basic idea. He defines profit in such a way that the interest on capital invested by the entrepreneur and the wages he receives for the activity of management is excluded; profit is merely a payment for the exercize of judgement involving risk and responsibility made necessary by uncertainty.

Friedrich Hayek, another pundit of the free enterprise philosophy, states : " According to the generally accepted view perfect competition presupposes... complete knowledge of the relevant factors on the part of all participants in the market " 24 .

Neoclassical theory presents a model from which the disturbing elements of reality are excluded, especially uncertainty about the future. Obviously this does not leave any room for insurance. If we were omniscient we would not have to protect ourselves against contingencies. But this Cartesian, Newtonian, mechanistic approach does accomplish more than that. It protects us against the anxieties and implicitly elevates the observing economist and the economic actor to the exalted level of an omniscient deity.

\section{The Heisenbergian paradigm}

I am using this term not so much in the sense in which it is used in quantum physics by physicists but as a symbol of the transition away from the Cartesian, Newtonian, mechanistic world outlook. This change transcends the sphere of physics and of economics; it was and is a fundamental change on all levels of historical existence.

This paradigm was developed by Werner Heisenberg in the so-called Heisenberg principle. However, its philosophical and epistemological implications were used before and have been used after Werner Heisenberg's findings. Its influence in philosophy and in the social sciences may be a direct or an indirect one. I am using the term not as an indication of a direct influence but to characterize a pattern of thought that has its roots in the historical conditions of the 20th century and transcends by far the boundaries of physics.

However, in physics the principle was stated in its most unequivocal form. Louis de Broglie asserted that the " scientific dogma " of determinism and, therefore, predictability, rested on the assumption that the observer and the observed natural world were completely separated. Heisenberg's principle of uncertainty (or indeterminacy) implies that - in microphysics - the influence of the observer on the position and the velocity of particles makes it impossible to ascertain both, their position and velocity, together. "This leads to a different view of reality : there is no complete causal determination of the future on the basis of available knowledge of the present. It means that every measurement... creates, a unique, not fully predictable situation. ... We cannot observe the course of nature without disturbing it." Niels Bohr has stated that "man is at once an actor and a spectator in the drama of existence" and Max Born compared the situation "to a football game where

${ }^{23}$ Ibid., pp. $76 \mathrm{ff}$. and Part I, chapter I, and Part III, chps. VIII, IX.

${ }^{24}$ Friedrich Hayek, Individualism and the Economic Order (Chicago : The University of Chicago Press, 1948), p. 95. 
the act of watching - applauding or hissing has an influence... on the players and thus on what is watched." 25

The steps that led to this fundamental change are known to every student of physics. The Cartesian view assumed final, indivisible, solid substantial units which were the building stones of the universe. The discovery that the atom is not a last indivisible unit but a universe in itself, and the doubts about the substantiality and reality of time and space shattered the Cartesian mechanistic world view completely. It pointed to an organic, holistic and "ecological" approach. The new system also indicated the dual nature of phenomena, especially of light which can take the form of electromagnetic waves or of particles, a duality which was called complementarity by Niels Bohr. The uncertainty about reality appears in the form of pairs of concepts " which are interrelated and cannot be defined simultaneously in a precise way". The new approach changed the image of reality: instead of being certain in time and space, it became probabilistic, a bundle of tendencies. The classical notion of reality as solid object was abolished. It appeared now as a wave-like pattern of probabilities. The basic openness of the universe appears as " a complicated web of relations between the various parts of a unified whole". What took place - and still is in process - is a shift from objects to relationships, and a shift from certainties to probabilities. ${ }^{26}$

\section{The system way of life}

The new paradigm that is connected with the name of Heisenberg is often identified with a system approach ${ }^{27}$. This, in contrast to the machine or clockwork approach of Descartes and Newton. The term is somewhat misleading. All thought implies some kind of a system. A machine and a clock are also systems. From the age-old mythologies to the modern sciences systems were in use. It is not the system concept as such which distinguishes the various sciences but the kind of system which they use. The relevant distinctions are : 1) between the number and kind of variables taken into consideration ; 2 ) how the interaction between these variables is interpreted and what kind of interaction is dealt with ; 3) whether the system is open or closed ; 4) whether the system aims at a determinate solution or results in indeterminacy. We have described how the mechanistic systems of the older capitalism tie in with the value-attitudes and institutions of their time. However, almost from the very inception of economics the restrictions and limitations of the mechanistic model were criticized from the social and philosophical point of view. The attempts to integrate social thought and philosophy go back a long way to the times of Carlyle and Ruskin and to the Historical School of economics in Germany. Since the development of sociology and anthropology integrationist thought has attempted to increase the number of variables, adding some that were borrowed from the younger social sciences. The image of the economic man whose behavior was exclusively motivated by maximizing his individual utility was modified by taking into account the influence of social interrelations, internalized values, communal relations and other non-economic

${ }^{25}$ Quotations from Ffloyd Matson, The Broken Image (New York : Braziller, 1964), pp. $140 \mathrm{ff}$.

${ }^{26}$ Fritjof Capra, loc. cit., pp. 78-81.

27 Ibid., pp. 265 ff., Schoeffler, loc. cit., ch. 4 ; Ludwig Bertalanffy, General Systems Theory (New York : Braziller, 1968). 
motives. Such endeavors did not change the character of a system. The mere enlargement of the number and type of variables included does not change it from a closed to an open system ; it remains closed as long as it is supposed to remain determinate if only all the known and knowable variables are included.

However, the new paradigm rests on another idea about the systems view of life or what is often called general systems philosophy. It was developed during and after the second World War and centered around cybernetics, computerization and artificial intelligence. This general systems view "looks at the world in terms of relationships and integration. Systems are integrated wholes whose properties cannot be reduced to smaller units". This idea represents an abandonment of mechanistic thinking whose paradigm was taken from classical physics and mechanics, and a change to a new organismic paradigm taken from biology. This kind of system rests on the principle of organization. ${ }^{28}$ Every organism is an integrated whole; that is what makes it into a living system. This applies equally to social systems such as the family, the neighborhood, the peer-group, the social class and the nation state. In such organisms the whole is different from the sum of its parts. General systemic and organismic thinking abandons explanation in terms of a single chain of causation, mere cause-and-effect reasoning where one factor is only cause and another mere effect. It visualizes reality as a network of chains, not of causation but of interrelations and interaction where cause and effect relation exists between all links of all chains. Every link is simultaneously both, cause and effect. The units of such an organismic patterned system stand to each other in the relationship of mutual, circular interdependence. Every unit produces a feedback, a reaction to its own action. ${ }^{29}$

The "organismic" biological model abandons the idea of unilinear, causal, mechanical links between indivisible units and looks synthetically at the whole. The Heisenbergian principle is part of this integrative trend; it repeals the sharp division between observer and observed, and arrives at a synthesis between the two. Heisenberg concluded that in science, ultimately, man encounters himself. That is another form of the "this art thou " of the mystics. The new idea is that man is a participant observer and can, therefore, never extricate himself from the shackles of his participation. This is another way of stating a truth that was embraced by mysticism East and West : that the I and the Thou, that the observer and the observed, that thought and reality, that man and his world are ultimately and essentially one. From the point of view of the Cartesian, Newtonian mechanistic thinking it appears as something negative because it blurs the distinction between subject and object. From the point of view of the new Heisenbergian, organismic, holistic paradigm it is the recognition of the unity of the cosmos which does not isolate man as an outsider but enables him to experience himself as part of being.

\section{The Heisenbergian paradigm in economics}

In physics this paradigm may be the logical outcome of relativity and quantum physics. Outside the natural sciences the turn towards a "Heisenbergian" orientation

28 Capra, loc. cit., pp. $266 \mathrm{ff}$.

${ }^{29}$ W. Weisskopf, Normative and Ideological Elements in Social and Economic Thought, Journal of Economic Issues, XI/1, March 1977, p. 104. 
reflects the disintegration of the Western belief system and of the changing character of capitalism.

The following events contributed to the changes in 19th century capitalism : 1) the growth of big business, monopolies, and market power; the countervailing power of government and labor unions ; 2) the disruption of the free market system in World War I ; 3) the Great Depression of the 1930ies which undermined the belief in the self-regulating powers and in the beneficiality of the free market. These events brought about a disappointment with the values of the existing system. The kinds of economic thought which turn away from determinate equilibrium theory and show Heisenbergian traits center around big business, market power and unemployment. The depression led to the conclusion that the self-regulating market had failed. Mass unemployment led to the conclusion that individual pursuit of gain in isolation from others does not protect the individual from economic disaster. This was aggravated by the growing of the market power of big business against which the small producer and consumer are helpless. The turn to a Heisenbergian paradigm thus reflects more than an epistemological reversal ; it is, in part, a phenomenon of disintegration of the old capitalism. However, like all historical events that change the old it contains the seeds of the new.

We find Heisenbergian trends in the dynamic approach of Schumpeter; in the theories of managerial capitalism; in imperfect and monopolistic equilibrium theory, and in Keynesianism.

The Newtonian paradigm was essentially static. We have shown how neoclassical equilibrium theory tried to eliminate time and change from its variables. This reductionism made it possible to arrive at a determinate equilibrium solution. In contrast, a dynamic approach was developed by $J$. A. Schumpeter ${ }^{30}$. He describes capitalism as $a$ process of creative destruction. He also stressed the importance of an entrepreneurial elite for economic progress. His hero is the innovating, adventurous entrepreneur who uses ever new methods in competition; but to Schumpeter competition was not a static process existing firms with constant technologies competing with each other. To him, competition is an evolutionary process. It is by " nature a form or method of economic change and never can be stationary... the fundamental impulse that sets and keeps the capitalistic engine in motion comes from the new consumers' goods, the new methods of production or transportation, the new markets, the new forms of industrial organization that capitalist enterprise creates... Competition is not a static system moving towards a static equilibrium under given conditions... where other things remain equal... It comes from the new commodity, the new technology, the new source of supply, the new type of organization (the largest-scale unit of control for instance). It strikes at the very foundation of all existing firms and organizations and tends to destroy while it creates the new; a never ending stream of creative destruction ". 31

This dynamic view represents an abandonment of the Newtonian paradigm and a turn to the Heisenbergian and general systems model. It stresses disequilibrium in contrast

${ }^{30}$ Joseph A. Schumpeter, Capitalism, Socialism, and Democracy (New York: Harper \& Brothers, 1950), ch. VII.

${ }^{31}$ Ibid. 
to equilibrium; uncertainty not predictability. Schumpeter does not assume that capitalism has changed from a static to a dynamic system ; for him capitalism was dynamic from its very beginning. What has changed, however, is the point of view from which capitalism was envisaged. Classical and neoclassical thought strenuously endeavored to show the market system to be stabilizing, equilibrating and determinate. Schumpeter tried to correct what to him were misapprehensions of traditional static equilibrium theory. However, the dynamic evolutionary approach of Schumpeter was a product of the corporate, monopolistic capitalism of the 20th century. Schumpeter does not deal with the problem of determinacy and indeterminacy; but his stress on the innovating, adventurous entrepreneur implies indeterminateness. Evolutionary, destructive and creative capitalism, driven forward by adventurous individuals must lead to indeterminate results because they include freedom of action as the most important variable. The shift to the Heisenbergian paradigm is also related to what I like to call managerialism. ${ }^{32}$ The change from atomistic competition to domination of the market by large corporations was accompanied by a shift in the seat of economic power from the owner-stockholder to the corporate manager. This line of thought goes back to James Burnham: The Managerial Revolution. ${ }^{33}$ Although this book was written from a Marxist point of view it described very well the second phase of capitalism. In this phase the basic economic decisions are not made by owners but by the managers of other peoples' assets, not only in socialist and communist systems but also in corporate capitalism. The corporate form of business organization promoted and made possible the separation of management and ownership. With the growing demotion of the stockholders from decisions makers to rentiers and quasi-creditors, the corporate managers became the decision-making elite. This destroyed the rationale for the free enterprise risk-taking which requires that the decision-makers suffer the punishment and reap the rewards of their decisions. In the managerial economy the managers - corporate and governemental managers - make the decision but the owners-stockholders suffer the punishments and reap the rewards. The position of the managers in the private sector shows little difference from the one of public employees ; both administer the assets of others and are only indirectly affected by the consequences of their decisions.

The growing size of corporations also affected the market situation. Firms of large size with a considerable share of the total market can administer their prices. Prices are not any more determined merely by supply and demand; they are set (within limits) by the policies of corporate managers. This changes the character of competition. It is not anymore pure price competition consisting in outbidding and underbidding. It is carried out largely by image building through advertising and by appealing to irrational consumers' preferences.

All this leads to an indeterminate, uncertain economic situation because the managers of large corporations can manipulate the market and the economy within wide margins.

32 Walter Weisskopf, Alienation and Economics (New York: E. P. Dutton, 1971, reprinted as paperback by Dell Publishing Company as Delta Book, 1973), pp. $130 \mathrm{ff}$. A. A. Berle and G. C. Means, The Modern Corporation and Private Property (New York: Macmillan, 1947), A. R. Burns, The Decline of Competition (New York: McGraw-Hill Book Company, 1936). E. S. Mason, The Apologetics of Managerialism, Journal of Business of the University of Chicago, $\mathrm{XXX} / 1$, January 1958.

${ }_{33}$ James Burnham, The Managerial Revolution, New York, 1941. 
If one adds to this the growing influence of corporations on politics, the image of a dominated, manipulated, fabricated economy and society emerges which corresponds to the action-oriented indeterminate Heisenbergian paradigm. The Heisenbergian principle led to the conclusion that in the observation of micro-nature man only encounters himself; in managerial, corporate economy man creates and then cognitively encounters his own creation.

The transition from the Newtonian to the Heisenbergian paradigm is thus a reflection of the changing character of capitalism. From a deterministic static system ruled by an invisible hand it changed to an indeterministic one ruled by deliberate conscious economic and political action. This distinction has been discussed for more than a century in terms of a free market versus planning; but this distinction is misleading; it led to an identification of planning with government. In the conservative movements in the USA and elsewhere the battle-cry is " business versus government". But this juxtaposition hides the strong element of manipulating action in the private sector where the visible hand is the hand of corporate management. The real distinction is between the invisible and the visible hand, between determinist and indeterminist systems.

\section{Monopolistic and imperfect competition theory}

These micro-economic equilibrium theories were first developed in the 1930ies, independently from each other in England by Joan Robinson and in the USA by Edward Chamberlin. ${ }^{34}$ Market power was previously neglected and pushed aside as an exception. The new theories tried to build it into the traditonal models. They acknowledged what economic reasoning has denied : the existence of market power. The way this was done is a classic example of the amalgamation of theory and ideology, of hiding a reversal in outlook behind a restructured theoretical frameworl. A new factor - market power was changed from an exogenous to an endogenous variable; but this was accomplished in such a way that the basic theoretical and ideological structure was seemingly preserved. ${ }^{35}$ It was assumed that a firm with market power is able to set the price it charges within the limit of a sliding scale (the famous declining demand curve). Thus, an increase of the firm's price over the prevailing market price would not lead to a complete loss of sales. The firm could still make profits at prices higher than the ones of its competitors. Such a firm could "administer" its prices and pursue all sorts of goals such as larger market share, smaller but stable long-run profits instead of short-run profit maximization, stability of operations through undisturbed relations with customers, suppliers, stockholders and labor unions, a favorable image in public opinion, etc. It could even pursue political, social, humanitarian and cultural goals.

Imperfect and monopolistic competition theory avoids this admission of the multiplicity of possible goals by assuming that short-run profit maximization is the only goal and that the firm knows its cost- and revenue curves. However, these assumptions

${ }^{34}$ Joan Robinson, The Economics of Imperfect Competition (London: Macmillan, 1933), Edward Chamberlin, The Theory of Monopolistic Competition (Cambridge : Harvard University Press, 1942).

${ }^{35}$ Walter Weisskopf, Alienation and Economics, pp. $118 \mathrm{ff}$. 
are not founded in economic reality; these curves are in reality expected future demand and cost curves and are actually unknown. This deprives the actions of producers of any certainty and determinacy. Also, the potential multiplicity of goals and the actions and reactions of oligopolistic firms with market power prevent the construct of a determinate equilibrium. When market power is present the decisions and actions of the individual sellers influence each others' decisions and actions. The mutual but indecisive indefinite influence opens the door to an infinite, varied pattern of possibilities. ${ }^{36}$ According to Professor Triffin this applies to the case of oligopoly where a few large firms share a market, a case of great importance in late capitalism where the key industries which determine a nation's economic fate, are of an oligopolistic character (steel, automobiles, machinery, chemicals, etc.)

This oligopolistic model with its indeterminate results shows definitely a Heisenbergian character. What makes it indeterminate is the absence of perfect knowledge and of perfect foresight, and the influence of this uncertainty on the actions and reactions of the marketers. The stress on action and interaction points to managerial capitalism and to the visible hand. It is also an example of general systems theory with cybernetic feedback and circular interdependency.

Professor Triffin assumes that "there is a sense in which the solution is always determinate, it all depends on the number of variables considered" ${ }^{37}$. Triffin believes that if one knew all the variables, even non-economic ones, one would arrive at a determinate solution "although it would be of a different type than the ones used by economics of the pure equilibrium brand."

Whether this is true depends upon one's answer to the question whether the universe is ultimately determinate or indeterminate. Our introductory ontological discussion leads to the belief in the ultimate indeterminateness of the universe, at least to the indeterminateness of the human world where final freedom exists. Be this as it may: the recognition of a multitude of variables influencing human behavior, together with the unpredictable choices made by the managers leads to a Heisenbergian indeterminacysituation.

\section{Keynesianism}

Keynesianism was a product of the second phase of capitalism ; but, like imperfect and monopolistic competition theory, it tried to accomplish a compromise between classical, determinate equilibrium theory and the new ideas of the second phase. It abandoned the individualistic, atomistic model of the economy which saw it as a composite of many indivisible solid units. Keynes laid the foundations to macro-economics, to thinking in economic aggregates. The economy is represented as a whole, as a general system in which all economic variables are mutually interdependent. Keynesianism, although still of a somewhat mechanistic " hydraulic" character, is the closest approach to a general cybernetic feedback system found in mainstream economics.

36 R. Triffin, Monopolistic Competition and General Equilibrium Theory (Cambridge : Harvard University Press, 1940), pp. 70 ff.

${ }^{37}$ Ibid., p. 77. 


\section{Epistemics}

Perhaps the most important turn in the direction of the Heisenbergian paradigm in economics can be found in the writtings of G.I.S. Shackle. ${ }^{38} \mathrm{He}$ concludes that the universe of human action and interaction - society, economy and polity - are indeterminate spheres of human existence. "Economics is about thought. It is therefore a branch or application of epistemics, the theory of thoughts." Because economists reduced their discipline to the consideration of things and neglected thought and inner processes, they disregarded " un-knowledge", the aboriginal state of man." Shackle, without using the term, criticized the deterministic Newtonian model in economics and the assumption of perfect knowledge of the future, " that vast and limitless area where knowledge is denied to us." He approves of the attempts of some economists, Keynes and Myrdal among them, to develop an economics of "fallible expectations". Because of ignorance of the future "expectations are not rational." This is clearly Heisenbergian thinking; the future is shaped by human action whose effects are unknown, unpredictable and indeterminate. Shackle demolishes the deterministic Newtonian model in which "un-knowledge" is assumed away.

\section{The meaning of the two paradigms}

In order to determine the meaning of the changes we have analyzed we have to remember that both, the Newtonian and the Heisenbergian paradigms, are symbolic belief systems originating in different periods of capitalism. We have pointed out the reasons why the Newtonian mechanistic determinism was and is on the decline. The old system does not any more perform the function of assuaging anxieties created by uncertainty and by ignorance. The replacement of the mechanistic, deterministic model by the Heisenbergian one, represents a process of replacement of one belief system by another, of one world outlook by another. Everything we have said above about validity and function of belief systems applies here. They are grounded in the historical conditions under which they were formulated. By abandoning the deterministic model, the basic ideology of early capitalism was also abandoned; the invisible hand which leads consumers' actions towards a harmonious beneficial equilibrium, the justification of egoistic action by the fiction that it benefits the public good were also abandoned. But the disintegration this abandonment implies goes further. Static order seems to yield to dynamic anarchy, certainty to uncertainty, order to disorder, determinacy to indeterminacy. Could it be that these trends are part of the causes that made our age into an age of anxiety? If one surveys Western history from the Middle Ages to the present, one sees a continuous disintegration of anxiety-reducing belief systems. The Heisenbergian paradign may be the result of a secular Western development. The medieval world outlook believed in a supernatural but comprehensible order. The Newtonian model believed in an order rooted in nature and comprehensible through reason. Having abandoned the belief in providence, grace and other-wordly rewards for religious virtue as well as the deterministic belief in nature and reason, the Heisenbergian paradigm seems to deprive us of all protection against the dread of the unknowable future and of the unknowable reality.

${ }^{38}$ G. L. S. Shackle, Epistemics and Economics (Cambridge: The University Press, 1972). Quotations are from the un-numbered Preface. 
However, both belief systems are of a dualistic nature. Each of them represents man as simultaneously omnipotent and impotent. The Newtonian paradigm enthrones man as a potentially omniscent observer of an objective reality, able to understand with his reason the logos-structure of the world. At the same time man is dethroned by being subjected to inexorable natural laws which unequivocally determine his fate. In microeconomic models the individual is allegedly able to know and to predict the future equilibrium price. In spite of this omniscience he is unable to influence this price or to deviate from it. This inner contradiction between an omniscient detached observer and an impotent economic actor - both one and the same person - is the essence of the competitive model. This contradiction is not restricted to the economic sphere; it is part of the Cartesian, Newtonian, deterministic world outlook; the individual is powerless in view of the laws of nature in spite of his potential omniscience. The Heisenbergian paradigm shows the same dualistic ambivalence; only the situation is reversed. The individual is bereft of his omniscience; events are not predetermined nor predictable. The impotence consists in unknowledge and in the unpredictability of the future. However, the Heisenbergian paradigm was part of the revolution in physics which made the splitting of the atom and hydrogen bombs possible with nuclear power as a byproduct. This has enhanced man's power over nature. In economics the new model is related to private and governmental market power and with managerial administration of the economy. Thus, power and powerlessness are synthesized in the Heisenbergian as well as in the Newtonian model, only in a different way. Newtonian man is powerful in his knowledge and his predictions but powerless in his actions. Heisenbergian man is powerless in his knowledge and in his predictions but powerful in his role as a participant in the evolutionary process of creation and destruction.

\section{Indeterminacy and cooperative action}

However, the disintegrative aspects of the turn towards indeterminacy are not the whole story. The positive side of the trend towards an indeterminate paradigm is its openness for human action. Hannah Arendt has pointed out that 20th century man tends to replace thought by action. ${ }^{39}$ Action implies not only freedom (within constraints) but, under conditions of plurality of people, cooperative planning. The dichotomy of Newtonian freedom of the market, so unfree for the powerless individual, and the Heisenbergian freedom to cooperate with others in planning the future is another example of dialectic dualism. If the future is predictable but, at the same time, beyond control, any interventionist action must be futile. Indeterminacy, however, cries for intervention. A socialist economist, Adolph Loewe, and a National-Socialist economist, Hans von Stackelberg, both arrived at the conclusion that indeterminacy and uncertainty should be counteracted by political action. ${ }^{40}$ Such action does not require an authoritarian system ; it can also be carried out - and is carried out - in democratic countries. What emerges under the impact of Heisenbergian thinking is a return to and a turn towards political

${ }^{39}$ Hannah Arendt, The Human Condition (Chicago : The University of Chicago Press, 1938), pp. $238 \mathrm{ff}$.

40 Adolph Loewe, On Economic Knowledge (New York: Harper \& Row, 1965). H. von Stackelberg, Marktform und Gleichgewicht (Wien und Berlin : 1923). 
economy; but even more so a turn towards the moral foundations of economics. These terms refer to the ultimately normative character of all economic questions. If, according to the Heisenbergian scheme, we cannot know what the future will be, we can still think about what it should be.

Most disputes in economics are about ends. How should resources be allocated ? What should be produced and who should get what? There are those who see in these normative questions mere conflicts of interests; they will see economics as the discipline of political economy. Those who believe that such questions are questions of ultimate goals and ends of human life will see economics as a moral science.

One can only hope that more economists will turn to the task of developing a new economic morality which would show us the way out of our present predicaments. 